\title{
SIGNIFICANCE OF ADENOSINE DEAMINASE LEVEL IN DIAGNOSIS OF TUBERCULOUS PLEURAL EFFUSION
}

\author{
Manabendra Nayak1, Sardhara Ashish Jayantibhai ${ }^{2}$
}

${ }^{1}$ Postgraduate Teacher of Medicine, NBE, Senior Consultant, Department of Medicine, Down Town Hospital. ${ }^{2}$ DNB Fellow of Medicine, Downtown Hospital, Guwahati, Assam.

ABSTRACT

\section{BACKGROUND}

Pleural effusion is a common chest problem, yet it is difficult to establish the aetiological diagnosis in as many as $20 \%$ cases in spite of good history, thorough clinical and radiological examination and pleural fluid analysis and pleural biopsy. ${ }^{1}$ There is a need of simple, rapid and reliable diagnostic test to establish the aetiology of pleural effusion. Many studies have investigated the usefulness of adenosine deaminase (ADA) in pleural fluid for the early diagnosis of tuberculous pleurisy.

\section{MATERIALS AND METHODS}

It was a time bound, hospital-based, case control study in the Department of Medicine, Downtown Hospital, Guwahati, Assam. All patients diagnosed with pleural effusion between Jan 2015 and Dec 2015 were studied; 30 patients were found to have tuberculous pleural effusion and 30 patients of non-tuberculous pleural effusion were taken for comparison. Pleural fluid ADA level was compared between tubercular and non-tubercular pleural effusion group and statistical analysis was done using SPSS software version 19

\section{RESULTS}

A total of 60 patients of age $>18$ years having pleural effusion were studied; 30 patients were in tubercular group and 30 patients were in non-tubercular pleural effusion group. Range of ADA in tuberculous group was $7-180 \mathrm{U} / \mathrm{L}$ with mean \pm SD $84.99 \pm 45.45$, while in non-tubercular group the range was $2-45.2 \mathrm{U} / \mathrm{L}$ with mean \pm SD $13.52 \pm 9.95$. We found a high significant (HS) difference in mean value of pleural fluid ADA level in each pair of groups when compared with tubercular group at .1\% level of significance. At a cut-off of $40 \mathrm{U} / \mathrm{L}$, the sensitivity and specificity of the test (pleural fluid ADA estimation for the diagnosis of tuberculosis) was $90.00 \%$ and $96.67 \%$ respectively, while the positive predictive value (PPV) and the negative predictive value (NPV) of the test was $96.43 \%$ and $90.62 \%$ respectively.

\section{CONCLUSION}

The method of ADA estimation is easy, simple and does not require expensive equipment. This test may find a place in routine investigation for early detection of TB in coming days and for differentiating tubercular from non-tubercular aetiology in pulmonary and extrapulmonary TB.

\section{KEYWORDS}

Adenosine Deaminase, Pleural Effusion, Tuberculosis.

HOW TO CITE THIS ARTICLE: Nayak M, Jayantibhai SA. Significance of adenosine deaminase level in diagnosis of tuberculous pleural effusion. J. Evolution Med. Dent. Sci. 2017;6(75):5340-5344, DOI: 10.14260/Jemds/2017/1160

\section{BACKGROUND}

India is the country with the highest burden of tuberculosis (TB). The World Health Organisation (WHO) statistics for 2014 give an estimated incidence figure of 2.2 million cases of TB for India out of a global incidence of 9 million. The estimated TB prevalence for 2014 is about 2.5 million. It is estimated that about $40 \%$ of the Indian population is infected with TB bacteria, the vast majority of whom have latent rather than active TB. ${ }^{2}$

Pleural tuberculosis accounts for less than $1 \%$ of all exudative effusions in western countries, occurring in only $3 \%-5 \%$ of tuberculous patients. However, in developing countries like India, it is responsible for $30 \%-80 \%$

Financial or Other, Competing Interest: None.

Submission 31-07-2017, Peer Review 07-09-2017,

Acceptance 12-09-2017, Published 18-09-2017.

Corresponding Author:

Dr. Sardhara Ashish Jayantibhai,

Downtown Hospital,

Guwahati, Assam

E-mail:dr.mnayak@yahoo.co.in

DOI: $10.14260 /$ jemds $/ 2017 / 1160$ of all pleural effusions encountered and may complicate tuberculosis in $31 \%$ of all cases. Thus, tuberculous pleuritis remains a major contributor to global morbidity and mortality. ${ }^{3}$

Conventionally, the diagnosis of tubercular pleural effusion is made on the basis of clinical data, biochemical and microscopic examination of pleural fluid which is nonspecific. Other methods are ZN staining and culture of pleural fluid lack sensitivity, i.e. $10 \%-40 \%$ and $8 \%-49 \%$ respectively. At the same time culture identification takes long time, i.e. 4 - 6 weeks. Pleural biopsy is an invasive procedure with sensitivity of $50 \%-80 \%$ and not a routine test. ${ }^{4}$ The levels of adenosine deaminase (ADA) are increased in tubercular pleural effusion and its determination has acquired popularity as a diagnostic test which is non-invasive, not expensive and is readily accessible.

The high sensitivity and specificity of ADA for an early diagnosis of tuberculous pleural effusion is promising. ${ }^{5}$ Several studies have suggested that an elevated pleural fluid ADA level predicts tuberculous pleuritis with a sensitivity and specificity of $90 \%-100 \% .5,6,7$ 
Objectives of the study was to compare the pleural fluid ADA level between tuberculous and non-tuberculous pleural effusion and to establish the diagnostic value of pleural fluid ADA level in tuberculous pleural effusion by using statistical methods.

\section{MATERIALS AND METHODS \\ Study Site}

Department of Medicine, Downtown Hospital, Guwahati, Assam.

\section{Study Population}

As per inclusion and exclusion criteria, patients were admitted to Downtown Hospital, Guwahati, Assam, who were found to have pleural effusion.

\section{Study Design}

Case control study.

\section{Time Frame to Address the Study}

One year of time duration from January 2015 to December 2015.

\section{Sample Size}

Sample Size was taken conveniently. A total of 60 patients were included. As it was a time bound study, out of all pleural effusion cases admitted during this time period 30 patients were found to have tuberculous pleural effusion. They were included in study group and for convenience 30 patients of non-tuberculous pleural effusion were taken for comparison.

\section{Inclusion and Exclusion Criteria}

Patients with age greater than 18 yrs., both male and female with pleural effusion (both exudative and transudative) were included in study. Patients with age less than 18 yrs. and those who do not wish to give the consent were excluded. Those who met the diagnostic criteria given below for TB were included in tubercular group (cases) and those who found to have alternate diagnosis and confirmed for absence of TB were included in non-tubercular group (control group).

\section{Definition of Cases}

Following diagnostic criteria were adopted for the diagnosis of tuberculous pleural effusion: Presence of the first or any two of the other criteria were used to label a case as tubercular; a. Bacterial confirmation of the presence of mycobacterium tuberculosis (Direct smear or culture or histological findings in tissue sample or fluids or TB-PCR in pleural fluid); b. FNAC or tissue biopsy with histopathological findings suggested of tuberculosis; c. Radiological findings suggestive of tuberculosis; d. Definitive clinical improvement within 2 months of anti-tubercular therapy; and e. A history of contact with open cases of tuberculosis and a positive reaction $>20 \mathrm{~mm}$ induration to 5 tuberculin unit (5TU) purified protein antigen.

\section{Definition of Controls}

Following diagnostic criteria were adopted for the diagnosis of the patients: 1 . Patients with enlarged cardiac shadow in plain x-ray chest with clinical or echocardiographic evidence of cardiac dysfunction with one or more of the mentioned alterations: pulmonary venous congestion on radiography, peripheral oedema, tachycardia or ventricular gallop were diagnosed as Congestive Heart Failure (CHF); 2. Patients having raised urea and creatinine levels in the presence of clinical evidence of fluid overload (e.g. Pulmonary or Peripheral oedema), radiologic evidence of renal parenchymal changes and an absence of malignancy or respiratory infections were diagnosed as chronic renal failure (CKD); 3. The presence of clinically and radiologically confirmed pneumonia with no direct or indirect evidence of bacterial presence suggested as Parapneumonic effusion; 4. Patients with pneumonia along with one or more of the following indicators of bacterial invasion of the effusion: presence of pus, bacteria in Gram's stain smear or culture, and $\mathrm{pH}$ under 7.0 or progressively decreasing to less than 7.20 was suggested as Empyema; 5. The presence of relevant auto-antibodies and clinical signs were aided in the diagnosis of Collagen vascular disease (CVD); 6. Pancreatitis was suspected in patients with history of severe deep boring abdominal pain and dyselectrolytaemia following a bout of heavy alcohol intake with relevant findings on abdominal ultrasound and raised serum amylase and lipase levels; 7. Patients with history of smoking, persistent cough, x-ray findings, cytological diagnosis of the pleural or Bronchoalveolar Lavage (BAL) and the elevated serum levels of specific tumour marker antigens were diagnosed as malignant pleural effusion; 8. Patients with history of chronic ethanol intake, low serum albumin level, evidence of ascites and chronic liver parenchymal changes on USG abdomen were diagnosed as chronic liver disease (CLD).

\section{Methodology}

The study was approved by the Ethics Committee of Downtown Hospital. All patients having age more than 18 yrs., having the symptoms and signs of pleural effusion, presenting during the course of hospital stay were evaluated and studied. 60 patients were included in the study according to convenience and above described inclusion and exclusion criteria. Proper consent was taken and patient identification number was given to each patient to protect their identity. General information of the patients including name, age, sex, marital status, occupation, address and contact number were asked and recorded in each case.

Presenting complaints were noted. Detailed present, past and family history was taken and recorded according to study proforma. Specific history in relation to respiratory diseases like fever and its evening rise pattern, loss of appetite, shortness of breath, dull ache, cough and expectoration were noted. Detailed general physical and systemic examination was done. Routine investigations like Hb, TLC/DLC, ESR, CBC, Chest $\mathrm{x}$-ray PA and Lateral views were done in all the cases. On the basis of radiological finding, patients were confirmed to be having pleural effusion. Ultrasound, ECG and some specialised tests were performed in different patients to confirm the diagnosis. Pleural fluid ADA estimation was done using Kit from Microxpress subdivision of Tulip Diagnostic (P) Ltd., India. ADA testing and reporting was done within 36 hours. A cut-off value of 40 was taken as ADA level positive.

\section{Statistical Methods}

Quantitative data were presented as mean and standard deviation (SD) values. For parametric data, Student's t-test was used for comparison between mean values of two groups 
and all calculations were done using SPSS software version 19. Result was presented in the form of sensitivity, specificity, predictive value and likelihood ratio.

\section{RESULTS}

A total of 60 patients of age $>18$ years having pleural effusion were studied. 30 patients were in tubercular group and 30 patients were in non-tubercular pleural effusion group. In tubercular group, Mean (SD) age was 47.8 (17.39) and male: female ratio was 1.73:1 and in non-tubercular group Mean (SD) age was 51.06 (16.17) and male: female ratio was 1.14:1. Further in non-tubercular group, 2 were congestive heart failure, 8 were chronic kidney disease, 6 were pneumonia, 2 were empyema, 3 were connective tissue disorders, 3 were pancreatitis, 4 were malignant and 2 were cirrhosis of liver.

\begin{tabular}{|c|c|c|c|c|c|c|}
\hline \multirow{2}{*}{\multicolumn{2}{|c|}{ Groups }} & \multicolumn{2}{|c|}{ ADA (U/L) } & \multirow{2}{*}{$\begin{array}{c}\text { SEM } \\
\text { SD/n }\end{array}$} & \multirow{2}{*}{ P-values } & \multirow{2}{*}{ Significance } \\
\hline & & Range & Mean \pm SD & & & \\
\hline & bercular $(n=30)$ & $7-180$ & $84.99 \pm 45.45$ & 8.35 & \multirow{3}{*}{0.0001} & \multirow{2}{*}{ Extremely Significant } \\
\hline & tubercular $(n=30)$ & $2-45.2$ & $13.52+9.95$ & 1.911 & & \\
\hline 1 & CHF $(n=2)$ & $6.5-8$ & $7.25+1.06$ & & & \\
\hline 2 & CKD $(n=8)$ & $2.9-17.5$ & $9.07 \pm 6.74$ & 2.468 & & \\
\hline 3 & Pneumonia $(n=6)$ & $14.5-38$ & $20.78+8.59$ & & & \\
\hline 4 & Empyema (n=2) & $8-10.2$ & $9.1 \pm 1.55$ & 2.236 & & \\
\hline 5 & CVD $(n=3)$ & $9-16$ & $13+3.60$ & & & \\
\hline 6 & Pancreatitis $(n=3)$ & $2.4-23$ & $9.8 \pm 11.46$ & 5.751 & & \\
\hline 7 & Malignant $(n=4)$ & $14.8-45.2$ & $24.55 \pm 14.08$ & & & \\
\hline 8 & $\operatorname{CLD}(n=2)$ & $2-7$ & $4.5+3.54$ & 2.318 & & \\
\hline
\end{tabular}

In Table 1, unpaired t-test was applied to find the significance difference of mean values of ADA between tubercular and nontubercular group, and we found a high significant (H.S.) difference at .1\% level of significance.

\begin{tabular}{|c|c|c|c|c|c|c|}
\hline $\begin{array}{c}\text { Aetiology according to } \\
\text { Set Criteria }\end{array}$ & $\begin{array}{c}\text { Cut-Off } \\
\text { Value of } \\
\text { ADA }\end{array}$ & $\begin{array}{c}\text { Number of True } \\
\text { Positive/ Negative } \\
\text { Cases }\end{array}$ & $\begin{array}{c}\text { Sensitivity } \\
\%\end{array}$ & $\begin{array}{c}\text { Specificity } \\
\%\end{array}$ & $\begin{array}{c}\text { Positive } \\
\text { Predictive Value } \\
\%\end{array}$ & $\begin{array}{c}\text { Negative } \\
\text { Predictive Value } \\
\%\end{array}$ \\
\hline Tubercular (n=30) & $>40$ & 27 & $90.00 \%$ & $96.67 \%$ & $96.43 \%$ & $90.62 \%$ \\
\hline Non-tubercular (n=30) & $\leq 40$ & 29 & \multicolumn{5}{|c|}{ Table 2. Statistical Analysis } \\
\hline \multicolumn{7}{|c|}{}
\end{tabular}

Out of 30 in Tubercular group 27 had ADA level $>40$ U/L (i.e. true positive), while 3 cases had ADA level $\leq 40 \mathrm{U} / \mathrm{l}$ (false negative) in which the ADA levels were ranged from 7 - $27 \mathrm{U} / \mathrm{L}$.

In non-tuberculous group ( $\mathrm{n}=30), 29$ cases had ADA levels $<40$ U/l (i.e. true negative) and only 1 case (malignant pleural effusion) had ADA level $>40 \mathrm{U} / \mathrm{l}$ being 45.2 (false positive).

Table 2 shows that at a cut-off of $40 \mathrm{U} / \mathrm{L}$, the sensitivity and specificity of the test was $90.00 \%$ and $96.67 \%$ respectively, while the positive predictive value (PPV) and the negative predictive value (NPV) of the test was $96.43 \%$ and $90.62 \%$ respectively.

\begin{tabular}{|c|c|c|}
\hline Parameter & Result & 95\% CI (Confidence Interval) \\
\hline Sensitivity & $90.00 \%$ & $73.47 \%$ to $97.89 \%$ \\
\hline Specificity & $96.67 \%$ & $82.78 \%$ to $99.92 \%$ \\
\hline Positive predictive value & $96.43 \%$ & $81.65 \%$ to $99.91 \%$ \\
\hline Negative predictive value & $90.62 \%$ & $74.98 \%$ to $98.02 \%$ \\
\hline Positive likelihood ratio & 27.00 & 3.92 to 186.16 \\
\hline Negative likelihood ratio & 0.10 & 0.04 to 0.30 \\
\hline Prevalence (\%) & $50.00 \%$ & $36.81 \%$ to $63.19 \%$ \\
\hline Table 3. Validation of ADA Test with a Cut-Off Value $>\mathbf{4 0}$ U/L for Patient for Diagnosing Tubercular Pleural Effusion \\
\hline
\end{tabular}

Statistical values were calculated and found to be: Sensitivity 90\% (at 95\% CI: 73.47\% to 97.89\%), specificity 96.67\% (at 95\% CI: $82.78 \%$ to $99.92 \%$ ), positive predictive value $96.43 \%$ (at $95 \%$ CI: $81.65 \%$ to $99.91 \%$ ), negative predictive value $90.62 \%$ (at $95 \%$ CI: $74.98 \%$ to $98.02 \%$ ), a positive likelihood ratio 27.00 (at 95\% CI: 3.92 to 186.16) and a negative likelihood ratio 0.10 (at 95\% CI:0.04 to 0.30). The disease prevalence of TB pleurisy in the studied population was 50\% (at 95\% CI: 36.81\% to 63.19\%). Diagnostic accuracy was $93.33 \%$.

\section{DISCUSSION}

Several researchers have reported that estimation of pleural fluid ADA is useful in establishing the aetiology of the effusion. Shibagaki $\mathrm{T}$ et $\mathrm{al}^{8}$ concluded that tuberculous pleural effusion had a much higher ADA activity than cancer effusion. Sharma et $\mathrm{al}^{9}$ found that levels of pleural fluid ADA were significantly higher than serum ADA levels in both tuberculous and non-tuberculous pleural effusions. Porcel JM et al ${ }^{10}$ found that a high ADA level is characteristic not only of lymphocytic, but also of neutrophilic TB effusions. An extremely high ADA activity should raise suspicion of tubercular empyema. Gupta et al ${ }^{11}$ concluded that the pleural fluid ADA levels were significantly higher in tuberculous exudative pleural effusions compared with non-tuberculous exudative pleural effusions. 
The present study included 60 patients; 30 were tubercular ranging from 20 - 80 years, while 30 were nontubercular from 21 - 80 years of age. In tubercular group mean \pm SD age was found to be $47.8 \pm 17.39$, while in nontubercular group collectively it was $51.06 \pm 16.17$.

In our study, confirmed cases were 30 in tubercular group. Out of these patients 27 had ADA level $>40 \mathrm{U} / \mathrm{L}$, while 3 cases had ADA level $\leq 40 \mathrm{U} / \mathrm{L}$. The ADA levels were ranged from 7 - $27 \mathrm{U} / \mathrm{L}$. In non-tuberculous group, out of 30 patients 29 cases had ADA levels $<40 \mathrm{U} / \mathrm{L}$ and only 1 case (Malignant) had ADA level $>40 \mathrm{U} / \mathrm{L}$ being 45.2. False positivity can also be due to empyema, lymphoma, malignancy, parapneumonic or collagen vascular disease. ${ }^{8}$

We calculated at a cut-off of $40 \mathrm{U} / \mathrm{L}$, the sensitivity and specificity of the test (pleural fluid ADA estimation for the diagnosis of Tuberculosis) was $90.00 \%$ and $96.67 \%$ respectively, while the positive predictive value (PPV) and the negative predictive value (NPV) of the test was $96.43 \%$ and $90.62 \%$ respectively.

PC Mathur et al ${ }^{12}$ studied pleural fluid ADA level in 120 pleural effusion patients, out of which 50 were tubercular pleural effusion. They found mean pleural fluid ADA level of $100 \mathrm{IU} / \mathrm{L}$, at cut-off of 40 sensitivity, specificity, PPV and NPV was $100,94.6,95.5$ and 100 respectively.

Burgess $\mathrm{LJ}^{13}$ showed ADA activity in tuberculous effusion was higher than in any other diagnostic group. At a level of 50 $\mathrm{U} / \mathrm{L}$, the sensitivity and specificity for the identification of tuberculosis was $90 \%$ and $89 \%$ respectively.

Number of studies have been done in which pleural fluid ADA cut-off levels ranged from 40 to $70 \mathrm{U} / \mathrm{L}$ and found that the sensitivity and specificity was comparable with our results as summarised in the table below.

\begin{tabular}{|c|c|c|c|c|c|c|c|c|c|}
\hline Authors & Country & Year & $\begin{array}{c}\text { Sample } \\
\text { Size }\end{array}$ & $\begin{array}{c}\text { Mean Pleural } \\
\text { Fluid ADA in } \\
\text { Tubercular Group }\end{array}$ & Cut-Off & Sensitivity & Specificity & PPV & NPV \\
\hline W Reechaipichitkul14 & Thailand & 2001 & 132 & $93.2 \pm 56.5$ & 48 & 80 & 80.5 & 71.43 & 86.85 \\
\hline Riantawan et al 15 & & 1999 & 216 & & 60 & 95 & 96 & - & - \\
\hline BK Gupta et al ${ }^{11}$ & India & 2010 & 96 & $67.34 \pm 22.85$ & 40 & 92 & 90 & 92.86 & 90 \\
\hline NA Helmy et al ${ }^{16}$ & Egypt & 2012 & 30 & $83.5 \pm 50.3$ & 30 & 80 & 85 & 84.2 & 81 \\
\hline Mo-Lung Chen et al ${ }^{17}$ & China & $(2004)$ & 147 & $78.17 \pm 24.76$ & 55 & 87.3 & 91.8 & 82.1 & 92.4 \\
\hline PC Mathur et al ${ }^{12}$ & India & 2004 & $50^{*}$ & 100 & 40 & 100 & 94.6 & 95.5 & 100 \\
\hline SK Verma et al ${ }^{18}$ & India & 2008 & 50 & 36 to 229.7 & 36 & 100 & 77.7 & - & - \\
\hline Sharma et al ${ }^{19}$ & India & 2001 & 75 & $95.8 \pm 57.5$ & 35 & 83.3 & 66.6 & - & - \\
\hline Mehta et al ${ }^{20}$ & India & 2014 & 122 & $64.11 \pm 32.33$ & 40 & 85.7 & 80.8 & 75 & 89.5 \\
\hline Kafle et al ${ }^{21}$ & Nepal & 2013 & 56 & 99.387 & 30 & 93.3 & 57.1 & 82.3 & 80 \\
\hline P Prabhakar Rao et al ${ }^{22}$ & India & 2015 & 50 & $84 \pm 11.8$ & 50 & 100 & 100 & - & - \\
\hline L. Valdes et al ${ }^{23}$ & Spain & 2010 & 218 & $118 \pm 40.6$ & 35 & 100 & 79.2 & 93.8 & - \\
\hline Present Study & India & 2015 & 60 & $84.99 \pm 45.45$ & 40 & 90 & 96.67 & 96.43 & 90.62 \\
\hline \multicolumn{10}{|c|}{ Table 4. Related Studies } \\
\hline
\end{tabular}

\section{CONCLUSION}

To conclude the method of ADA estimation is easy, simple and does not require expensive equipment. It is economical and less time consuming (takes only two hours). This test may find a place in routine investigation for early detection of TB in coming days and for differentiating tubercular from non-tubercular aetiology in pulmonary and extrapulmonary TB.

In this study, ADA levels in non-tuberculous exudative pleural effusions rarely exceeded the cut-off set for tuberculous disease. The pleural fluid ADA levels were significantly higher in tuberculous exudative pleural effusions when compared with non-tuberculous exudative pleural effusions. Adenosine deaminase level of less than $40 \mathrm{U} / \mathrm{L}$ practically excludes the tubercular aetiology in exudative pleural effusion cases and thus may be useful in differentiating tuberculous aetiology from others in exudative pleural effusion.

The diagnostic utility of ADA in tuberculous pleural effusions has been evaluated. This case control study provides additional evidence that ADA levels in nontuberculous pleural effusions seldom exceed the cut-off set for tuberculous effusions. Mean pleural fluid ADA level was significantly higher in tuberculous pleural effusion. Low ADA levels in lymphocytic pleural effusions virtually exclude the diagnosis of tuberculosis.

\section{REFERENCES}

[1] Kataria YP, Imtiaz K. Adenosine deaminase in the diagnosis of tuberculous pleural effusion. Chest 2001;(2):298-300.

[2] Global Tuberculosis Control. WHO, Geneva, 2015.

[3] Udwadia ZF, SenT. Pleural tuberculosis: an update. Curr Opin Pulm Med 2010;16(4):399-406.

[4] Jay SJ. Diagnostic procedures for pleural diseases. Symposium of pleural diseases. Clin Chest Med 1985;6(1):33-48.

[5] Ghelani DR, Parikh FS, Hakim AS, et al. Diagnostic significance of immunoglobulins and adenosine deaminase in pleural effusion. J Assoc Physicians India 1999;47(8):787-90.

[6] Jimenez DG, Diaz G, Perez-Rodriguez E. Diagnosis of pleural tuberculousis. Chest 2002;121(3):1005.

[7] Hamada T, Sanaka M, Hata E, et al. Pleural adenosine deaminase levels in tuberculous pleurisy- its diagnostic performance under different prevalences in different age of population. Jpn J Thorac Cardiovascular Surg 1998;46(1):51-7.

[8] Shibagaki T, Hasegawa Y, Saito H, et al. Adenosine deaminase isozymes in tuberculous pleural effusion. J Lab Clin Med 1996;127(4):348-52. 
[9] Sharma SK, Mohan A. Adenosine deaminase in diagnosis of tuberculosis pleural effusion. Indian J Chest Dis Allied Sci 1996;38:69-71.

[10] Porcel JM, Vives M. Etiology and pleural fluid characteristics of large and massive effusions. Chest 2003;124(3):978-83.

[11] Gupta BK, Bharat V, Bandyopadhyay D. Role of adenosine deaminase estimation in differentiation of tuberculous and non-tuberculous exudative pleural effusions. J Clin Med Res 2010;2(2):79-84.

[12] Mathur PC, Tiwari KK, Trikha S, et al. Dignostic value of ADA activity in Tubercular serositis. Indian J Tuberculosis 2006;53(2):92-5.

[13] Burgess LJ, Maritz FJ, Le Roux I, et al. Combined use of pleural adenosine deaminase with lymphocyte/neutrophil ratio. Increased specificity for the diagnosis of tuberculous pleuritis. Chest 1996;109(2):414-9.

[14] Reechaipichitkul W, Kawamatawong T, Teerajetgul Y, et al. Diagnostic role of pleural fluid adenosine deaminase in tuberculous pleural effusion. Southeast Asian J Trop Med Public Health 2001;32(2):383-9.

[15] Riantawan P, Chaowalit P, Wongsangiem M, et al. Diagnostic value of pleural fluid adenosine deaminase in tuberculous pleuritis with reference to HIV coinfection and a Bayesian analysis. Chest 1999;116(1):97-103.

[16] Helmy NA, Eissa SA, Masoud HH, et al. Diagnostic value of adenosine deaminase in tuberculous and malignant pleural effusion. Egypt J Chest Dis Tuberc 2012;61(4):413-7.
[17] Chen ML, Yu WC, Lam CW, et al. Diagnostic value of pleural fluid adenosine deaminase activity in tuberculous pleurisy. Clin Chim Acta 2004;341(12):101-7.

[18] Verma SK, Dubey AL, Singh PA, et al. Adenosine deaminase (ADA) level in tubercular pleural effusion. Lung India 2008;25(3):109-10.

[19] Sharma SK, Suresh V, Mohan A, et al. A prospective study of sensitivity and specificity of adenosine deaminase estimation in the diagnosis of tuberculosis pleural effusion. Indian J Chest Dis Allied Sci 2001;43(3):149-55.

[20] Mehta AA, Gupta AS, Ahmed S, et al. Diagnostic utility of adenosine deaminase in exudative pleural effusions. Lung India 2014;31(2):142-4.

[21] Paudel YP, Kasyap AK, Dongol Y, et al. Pleural fluid adenosine deaminase (ADA) level in tuberculous pleurisy. Journal of Chitwan Medical College 2013;3(5):26-7.

[22] Rao PP, Devi VI, Sujatha C, et al. Assessment of adenosine deaminase in extra pulmonary tuberculosis. Int J Recent Sci Res 2015;6(9):6522-4.

[23] Valdés L, José SME, Pose A, et al. Diagnosing tuberculous pleural effusion using clinical data and pleural fluid analysis: a study of patients less than 40 years-old in an area with a high incidence of tuberculosis. Respir Med 2010;104(8):1211-7. 